\title{
Assessment the Operational Risk for Chinese Commercial Banks*
}

\author{
Lijun $\mathrm{Gao}^{1,2}$, Jianping $\mathrm{Li}^{2, * *}$, Jianming $\mathrm{Chen}^{2}$, and Weixuan $\mathrm{Xu}^{2}$ \\ ${ }^{1}$ Graduate University of Chinese Academy of Sciences, Beijing 100039, P.R. China \\ glj963217@163.com \\ ${ }^{2}$ Institute of Policy \& Management, \\ Chinese Academy of Sciences, Beijing 100080, P.R. China \\ \{ljp, jmchen, wxu\}@casipm.ac.cn
}

\begin{abstract}
Operational risk is one of the most important risks for Chinese commercial banks, and brings huge losses to Chinese commercial banks recent years. Using the public reported operational loss data from 1997 to 2005 of Chinese commercial banks, we simulate the operational loss distribution, find that loss frequency can be seen as Poisson distribution and the logarithm of loss is normal distribution. In accordance with the confidence level required by Basel II, aggregated loss distributions and operational Value-at-Risks (OpVaR) are calculated by Monte Carlo Simulation. Comparing with the real loss, this result is credible. We also calculate the economic capital by the $V_{a R_{99.9}}$, and it maybe help the banks to allocate appropriate their economic capital.
\end{abstract}

\section{Introduction}

Operational risk has gradually become an area of risk management in global banking. The increase of sophisticated and complex banking practices have raised the needs for an effective operational risk management and measurement system both to regulators and financial industry. In the aspect of definition, the Risk Management Group (RMG) of the Basel Committee and industry representatives have agreed on a standardized definition of operational risk[1], i.e. "the risk of loss results from inadequate or failed internal processes, people and systems or from external events". This definition, which includes legal risk and excludes strategic and reputation risk, relies on the categorization of operational risks based on the underlying causes[2].

Operational risk is mainly triggered by human error, system malfunction, and operational procedure mistake or control invalidation. It may result in huge loss of financial institutes. There are some well-known cases such as the Barings' bankruptcy in 1995, the $\$ 691$ million trading loss at Allfirst Financial[3], LTCM, Natwest, and Allied Irish Bank[4], and the \$140 million loss at the Bank of New York due to September $11^{\text {th }}$.

\footnotetext{
* This research has been partially supported by a grant from National Natural Science Foundation of China (\#70531040), the President Fund of Chinese Academy of Sciences (yzjj946) and 973 Project (\#2004CB720103), Ministry of Science and Technology, China.

* Corresponding author.
} 
Due to the growth of e-commerce, large-scale mergers and acquisitions, the enrichment of financial service products, and the use of more highly automated technologies, the probability of operational risk is increasing [5].

There have been several operational losses recently in Chinese commercial banks, such as the cheating case in Heilongjiang branch of Bank of China, the 4 billion loan deceived in Kaiping, etc.. The Chinese financiers and researchers have paid high attention to banks' operational risks, but there have no effective measurements to operational risk[6]. It is critical to improve the operational risk management of Chinese commercial banks.

Many of the operational risk models [7-8] such as Advanced Measurement Approaches (AMA), function correlation approach, causal models and Bayesian models, actuarial models, etc., are restricted for applying to the Chinese commercial banks by lacking of credible internal loss database. As the Monte Carlo simulation can overcome the deficiency of data by effective simulation and producing relative exact data, we use Monte Carlo Simulation to get OpVaRs and economic capital estimates for operational risk, this can help banks improve internal control and spur banks improving operational risk management.

The paper is organized as follows: In section 2, we discuss the simulation method we used; section 3 describe the original data; section 4 presents the simulation results and analysis, including the testing of the distribution of the historic operational loss data, and calculation on the operational economic capital, and the result analysis; The last past concludes the paper and introduces some future research directions.

\section{The Simulation Method}

Two parameters are commonly used to describe operational risk: the frequency and the loss amount. If the loss frequency and the loss amount follow certain distributions, and the statistical distribution of frequency and the loss are stable, we can use historic loss data to estimate their distribution and operational loss.

We use Monte Carlo simulation compute the frequency and the loss distributions[9]. Different OpVaRs are then simulated. The steps of the method are described as follows:

Step1. Collect historic loss data of operational events; estimate the loss frequency and the loss, Normal distribution, uniform distribution, Poisson distribution and exponential distribution are tested to find a most suitable distribution;

Step2. After generating the frequency distribution, we generate 1000 random numbers approximate to the distribution, representing the events for 1000 simulated periods.

Step3. For each period, generate required random number of loss (that is, if the simulated events for period $\mathrm{k}$ is $\mathrm{X}$, then simulate $\mathrm{X}$ losses) and add them to get the aggregated loss for the period.

Step4. Run steps 1 to 3 ten times and take the average OpVaR as the final result.

\section{The Data Set}

We have collected operational losses of Chinese commercial banks from 1997 to 2005 by public report, such as the website of National Audit Office of the P.R.C., website of china banking regulatory commission, finance news of banks cases and 
others, which counts 45 loss events, including 8 major commercial banks. Table 1 is describing the number events of each year, and Fig. 1 is the histogram of loss events.

Table 1. The number of operational loss events from 1997 to 2005

\begin{tabular}{|c|c|c|c|c|c|c|c|c|c|}
\hline Year & 1997 & 1998 & 1999 & 2000 & 2001 & 2002 & 2003 & 2004 & 2005 \\
\hline $\begin{array}{c}\text { Num- } \\
\text { ber }\end{array}$ & 5 & 4 & 1 & 3 & 4 & 13 & 5 & 3 & 7 \\
\hline
\end{tabular}

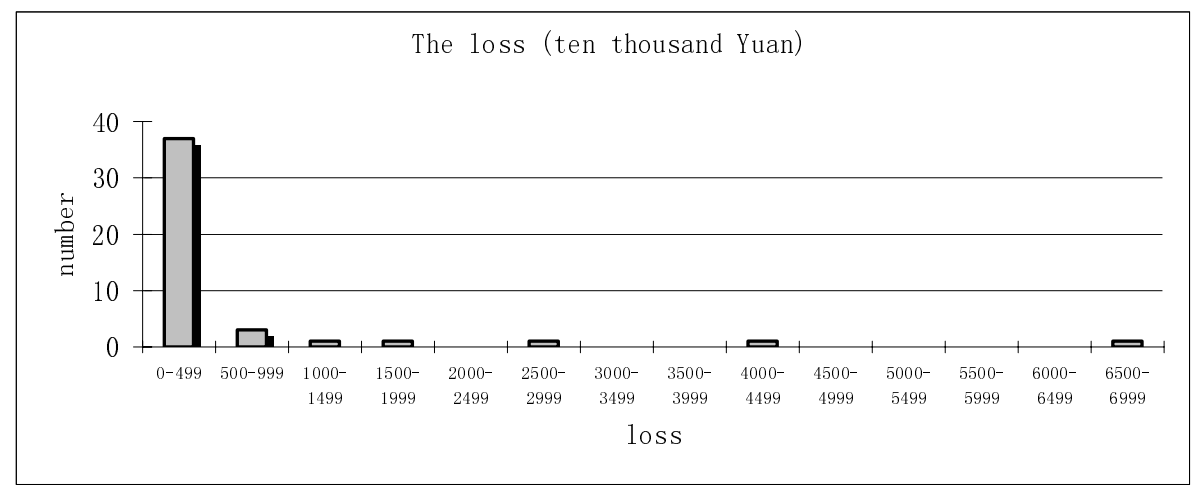

Fig. 1. Loss histogram of 1997-2005

\section{Simulation Results and Analysis}

\subsection{Testing on the Loss Frequency Distribution and Loss Distribution}

The loss varies significantly and most losses are under 5 million Yuan, so we test 11 curve regressions to simulate the loss distribution, and find that the logarithmic fits the data best. The result of curve estimations is shown in table 2, Fig. 2 is the logarithmic value of Fig.1; the software we used is SPSS 11.5.

Table 2. The loss curve estimation

\begin{tabular}{|r|r|r|r|r|}
\hline Curve & Function & F value & Rsq. & Sig. \\
\hline Linear & $\mathrm{Y}=20.1204+6.0 \mathrm{E}-05 \mathrm{x}$ & 19.28 & 0.310 & 0.000 \\
\hline Logarithmic & $\mathrm{Y}=-23.037+5.2928 \ln x$ & 850.38 & 0.952 & 0.000 \\
\hline Inverse & $\mathrm{Y}=25.3719-955.32 / \mathrm{x}$ & 16.35 & 0.276 & 0.000 \\
\hline Quadratic & $\mathrm{Y}=17.2152+0.0002 \times-3 . \mathrm{E}-10 \mathrm{x} 2$ & 24.59 & 0.539 & 0.000 \\
\hline Cubic & $\mathrm{Y}=13.8314+.0005 \mathrm{x}-2 . \mathrm{E}-09 \times 2+1.6 \mathrm{E}-15 \mathrm{x} 3$ & 41 & 0.75 & 0.000 \\
\hline Power & $\mathrm{Y}=15.4421(1.0000 \mathrm{x})$ & 7.29 & 0.145 & 0.01 \\
\hline Compound & $\mathrm{Y}=0.8556 \mathrm{x} 0.3478$ & 443.87 & 0.912 & 0.000 \\
\hline S-curve & $\mathrm{Y}=\mathrm{e} 3.1141-98.559 / \mathrm{x}$ & 79.97 & 0.65 & 0.000 \\
\hline Logistic & Unfitted & \\
\hline Growth & $\mathrm{Y}=\mathrm{e} 2.7371+2.7 \mathrm{E}-06 \mathrm{x}$ & 7.29 & 0.145 & 0.01 \\
\hline Exponential & $\mathrm{Y}=15.4421 \mathrm{e} 2.7 \mathrm{E}-06 \mathrm{x}$ & 7.29 & 0.145 & 0.01 \\
\hline
\end{tabular}


Based on table 1 and Fig. 2, we estimate the loss frequency distribution and loss distribution, test the normal distribution, uniform distribution, Poisson distribution and exponential distribution separately to find a most suitable distribution, and use the Kolmogorov-Smirnov (K-S) test to reject or accept the null hypothesis that the data originate from the selected distribution with the estimated parameters. Table 3 shows the result.

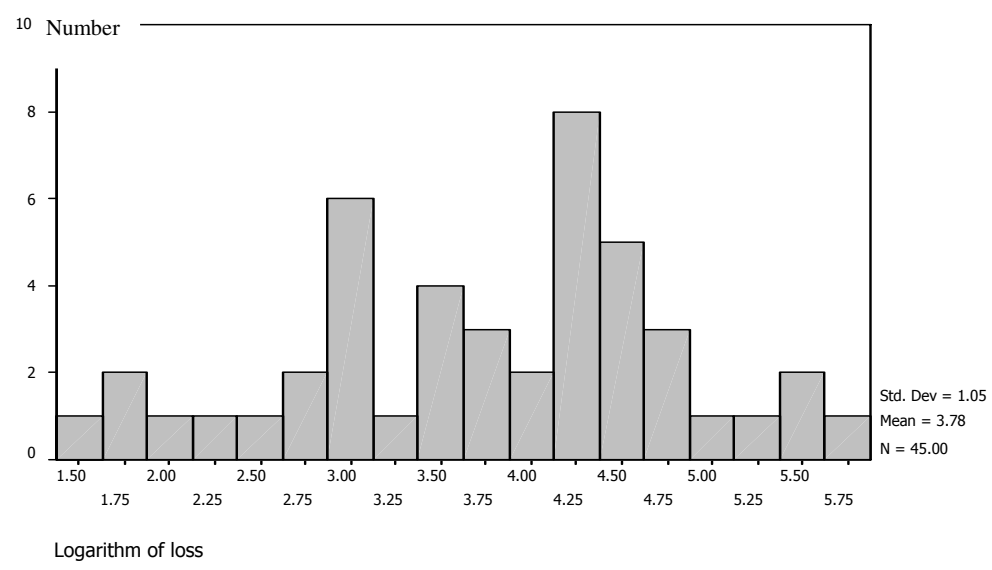

Fig. 2. Logarithm of loss histogram of 1997-2005

Table 3. Distribution test

\begin{tabular}{|l|l|c|c|c|c|c|}
\hline & \multicolumn{3}{|c|}{ Loss severity distribution } & \multicolumn{2}{c|}{ Loss frequency distribution } \\
\hline $\begin{array}{c}\text { urve distribu- } \\
\text { tion }\end{array}$ & Mean/Stdev. & K-S Z & $\begin{array}{c}\text { Asymp. } \\
\text { Sig. }\end{array}$ & $\begin{array}{c}\text { Mean/std } \\
\text { ev }\end{array}$ & K-S Z & $\begin{array}{c}\text { Asymp. } \\
\text { Sig. }\end{array}$ \\
\hline Normal & $3.7775 / 1.0514$ & 0.696 & 0.718 & $5 / 3.428$ & 0.833 & 0.491 \\
\hline Uniform & $\begin{array}{c}1.41 / 5.84 \\
\text { (max/min) }\end{array}$ & 1.192 & 0.117 & $\begin{array}{c}1 / 13 \\
\text { (max/min) }\end{array}$ & 1.333 & 0.057 \\
\hline Poisson & \multicolumn{3}{|c|}{ Unfitted } & 5 & 0.485 & 0.972 \\
\hline Exponential & 3.7775 & 2.594 & .000 & 5 & 1.02 & 0.249 \\
\hline
\end{tabular}

The results indicate that normal distribution and Poisson distribution fit the logarithmic of loss and loss frequency better than all other distributions. As shown in table 3 , the loss frequency distribution is approximately 5 events per year. Considering the historic logarithm of loss distribution, the skewness is -0.354 , while the standard deviation of skewness is 0.354 , then the data can be regarded as symmetry, the kurtosis is -0.231 , so we can conclude that the logarithm of single loss distribution follows normal distribution.

\subsection{The Losses Under Different Confidences}

After we get the single loss distribution, we can calculate the OpVaRs under different confidences, table 4 shows the result. 
Table 4. The OpVaRs under different confidences of single loss

\begin{tabular}{|c|c|c|c|}
\hline $\operatorname{VaR}_{25}$ & $\operatorname{VaR}_{50}$ & $\operatorname{VaR}_{75}$ & $\operatorname{VaR}_{90}$ \\
\hline 1170.347 & 5991.009 & 30667.99 & 133344.5 \\
\hline $\operatorname{VaR}_{95}$ & $\operatorname{VaR}_{99}$ & $\operatorname{VaR}_{99.9}$ & $\operatorname{VaR}_{99.99}$ \\
\hline 321340 & 1673071 & 10634453 & 48741655 \\
\hline
\end{tabular}

Then we can compute the aggregated loss in a one-year period, the steps are:

Step1: Generate the Poisson random variables $n_{1}, n_{2}, \cdots, n_{1000}$;

Step2: If $n_{i}=k_{i}$, then generate $k_{i}$ normal random variables, add them up and result is the loss this period;

Step3: Run steps 1 to 2 ten times and take the average as the value;

Step4: Using the 1000 potential loss to get the operational loss.

The aggregated loss is simulated, and we get some important statistical data, the mean of the loss per year is 4659.799 million Yuan, while the standard deviation is 1246536.699.

As the new Basel Committee[10] required that the regulatory capital that covers the operational risks over a one-year period within a confidence interval of $99.9 \%$, we compute the $V a R_{99.9}$, and other typical points of confidence level are shown as table 5:

Table 5. The aggregated operational confidence level in one year (ten thousand Yuan)

\begin{tabular}{|c|c|c|c|}
\hline VaR $_{25}$ & VaR $_{50}$ & $\operatorname{VaR}_{75}$ & $\operatorname{VaR}_{90}$ \\
\hline 42325.3 & 126969.7 & 377572.2 & 996322.6 \\
\hline $\operatorname{VaR}_{95}$ & $\operatorname{VaR}_{99}$ & $\operatorname{VaR}_{99.9}$ & $\operatorname{VaR}_{99.99}$ \\
\hline 1854812 & 5845208 & 17607593 & 85841937 \\
\hline
\end{tabular}

So the aggregate loss distribution as following Fig. 3:

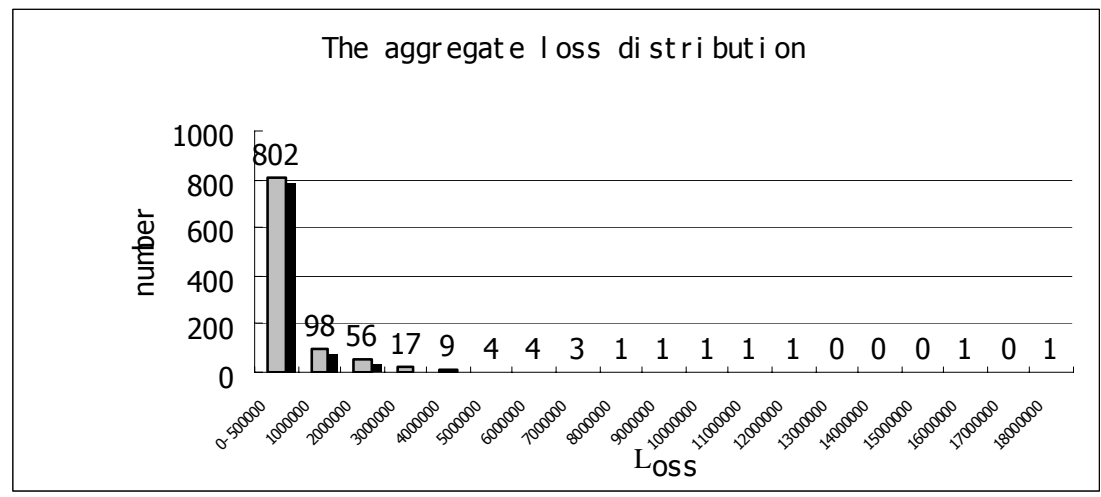

Fig. 3. The aggregate loss distribution 


\subsection{Result Analysis}

\subsubsection{There is Huge Potential Operational Loss in Bank System}

Most losses are not huge and there are 802 losses under 5 billion Yuan, there are 900 events below 10 billion Yuan, but there may be very huge loss a year and the biggest loss we simulated is 176 billion, which can do harm to the survival of the banks.

\subsubsection{The Loss Severity Affects the Aggregate Loss Distribution Much}

Although the aggregate loss distribution is generated by the loss frequency and loss severity, the influence of the two distributions on the aggregate loss distribution is not equal, from table 4 and table 5 we can conclude that loss frequency distribution only affect the aggregate loss distribution slightly, especially for the tail distribution, and the higher frequency in one year, the less influence to aggregate loss; While the loss severity affect the aggregate loss distribution much more, which makes the curve of aggregate loss distribution is somewhat like the single loss distribution.

\subsubsection{The Proposed Operational Economic Capital}

Our purpose is not only to work out the aggregate loss distribution of operational loss, but also use it to help determine the approximate operational economic capital of Chinese commercial banks. Based on the results in 4.2, we can calculate the operational economic capital of Chinese commercial banks:

Economic capital $=V a R_{99.9}$-mean $=16707593-465979.9=17141613.1 \quad($ Ten thousand $)$ So according to the new Basel committee's suggestion, Chinese commercial banks as a whole, should prepare 171.42 billion Yuan for operational loss.

4.3.4. The method and results are comparatively credible.

We present a simulation method and get some results to the operational risk, to verify the result. The result is tested by two ways.

The first way is to use the aggregate loss distribution to map the 1000 periods to 9 periods and then comparing them with the real loss from 1997 to 2005. Table 5 shows the detail.

Table 6. The result compared with the real data (9 years)

\begin{tabular}{|c|c|c|c|c|c|}
\hline \multirow{2}{*}{ Frequency } & \multicolumn{5}{|c|}{ Loss(billion) } \\
\cline { 2 - 6 } & $0-5$ & $5-10$ & $0-2$ & $2-4$ & $4-5$ \\
\hline Simulated (times) & 7 & 1 & 6 & 1 & 0 \\
\hline Real (times) & 8 & 1 & 6 & 1 & 1 \\
\hline
\end{tabular}

The simulated result is almost the same with real time, for example, the simulate result shows that there is only one year's losses between 5 to 10 billion if the period is 9 years, and the real data is 1 . This comparison study shows that the simulation results are pretty good.

Second, since we simulated 1000 random data of loss frequency, according to the theoretical result, there is about one number bigger $V a R_{99.9}$, or about 10 numbers bigger than $V a R_{99.9}$, etc.. Table 6 shows the 4 group compared results. 
Table 7. The estimation of OpVaRs

\begin{tabular}{|c|c|c|c|c|}
\hline Frequency & $>^{V_{99.9}}$ & $>^{\operatorname{VaR}}{ }_{99}$ & $>^{V_{92}}{ }_{95}$ & $>^{\operatorname{VaR}_{90}}$ \\
\hline Theoretical & 1 & 10 & 50 & 100 \\
\hline Simulated & 0 & 11 & 50 & 101 \\
\hline
\end{tabular}

Although there is no number bigger than the $\operatorname{VaR}_{99.9}$, the biggest one in our simulation is 176.07135 billion, which is very close to the $\operatorname{VaR}_{99.9}$ (176.07593 billion). The other three also accord with the theoretical result very well. It shows the simulation is reasonable.

\section{Conclusions}

Many operational models can't be used to measure operational risk efficiently for Chinese banks since Chinese commercial banks having little operational loss data and it is critical to quantify the operational loss. In this paper, we present a simulation method to the Chinese commercial banks as a whole, find that the logarithmic of loss follows the normal distribution while the loss frequency follows the Poisson distributions. We calculate the OpVaRs, and compare them to the real loss data per year. The results show that our method is comparatively reasonable and creditable, and the supervision capital we calculated may help the regulators to determine the operational economic capital.

Since the loss data is small, our simulation may be not exactly correct. If we have more operational loss data, we will re-calculate the certain bank's operational losses, and test more models such as the Multiple-Criteria Programming [11,12], Support Vector Machines[13] to find more suitable model. The model proposed in this paper may be also used in general bioinformatics, any antibody and any antigen.

This is our further work.

\section{References}

1. Basel Committee on Banking Supervision. Operational Risk, Consultative Document. Basel, September 2001, URL: http://www.bis.org.

2. The Basel Committee on Banking Supervision Bank for International Settlements CH4002 Basel. Third consultative paper(CP3) on the New Basel Capital Accord. Switzerland, July 30, 2003.

3. Hubner G., Peters J-P, Plunus S. Measuring operational risk in financial institutions: Contribution of credit risk modeling, March 2005.

4. Helbok G., Wagner C. Corporate financial disclosure on operational risk in the banking industry. Working Paper, September 2004.

5. Cornalba C., Giudici P. Statistical models for operational risk management. Physical A, 338, 2004, 166-172.

6. Gao, L.J, Li J.P., Chen, J.M, Wang, S.P. A New Assessment of Operational Risk of commercial bank: OpRisk+ Model, Chinese Journal of Management Science(S). 2005, Vol.13:185-188 (in Chinese). 
7. Patrick F., Eric R., Jordan J. Implications of alternative operational risk modeling techniques. NBER Working Paper No. 11103, June 2004. http://papers.nber.org/ papers/W11103

8. Alexander C. Statistical models of operational loss. In Operational Risk. Regulation, Analysis and Management, FT Prentice Hall Financial Times, 2003, 129-170.

9. Peters J.P., Crama Y., Hubner G. Basel II project: computation of OpVaR, Working Paper, 2003. HEC Management School, University of Liège.

10. Basel II: International Convergence of Capital Measurement and Capital Standards: a Revised Framework, Basel Committee Publications, June 2004.

11. Shi, Y., Peng, Y., Kou, G., Chen, Z . Classifying Credit Card Accounts for Business Intelligence and Decision Making: A Multiple-Criteria Quadratic Programming Approach. International Journal of Information Technology and Decision Making, Vol. 4, No. 4 (2005) 1-19.

12. Kou, G., Peng, Y., Shi, Y., M. Wise, Xu, W.X. Discovering Credit Cardholders' Behavior by Multiple Criteria Linear Programming. Annals of Operations Research 135 (1): 261274, JAN 2005.

13. Li, J.P, Liu, J.L, Xu, W.X., Shi, Y. Support Vector Machines Approach to Credit Assessment. In Bubak, M., Albada, G.D.v., Sloot, P.M.A., Dongarra, J.J. (Eds.) , ICCS 2004, LNCS 3039, Springer-Verlag, Berlin, 892-899, 2004. 